\title{
Irradiation Testing of Ultrasonic Transducers
}

\author{
ANIMMA \\ J. Daw \\ B. Tittmann \\ B. Reinhardt \\ G. Kohse \\ P. Ramuhalli \\ R. Montgomery \\ $\mathrm{H}-\mathrm{T}$ Chien \\ J-F Villard \\ J. Palmer \\ J. Rempe
}

The INL is a

U.S. Department of Energy

National Laboratory

operated by

Battelle Energy Alliance

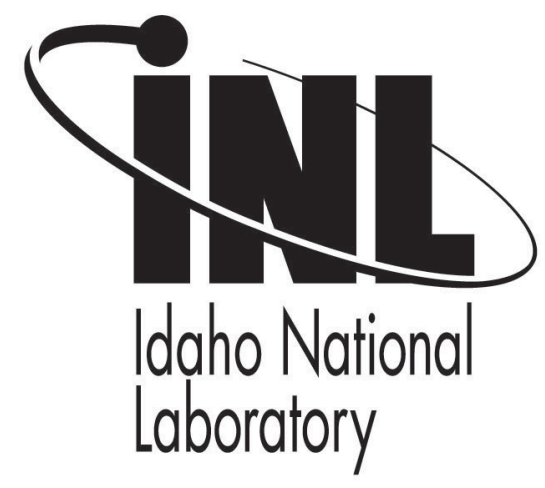

\section{June 2013}

This is a preprint of a paper intended for publication in a journal or proceedings. Since changes may be made before publication, this preprint should not be cited or reproduced without permission of the author. This document was prepared as an account of work sponsored by an agency of the United States Government. Neither the United States Government nor any agency thereof, or any of their employees, makes any warranty, expressed or implied, or assumes any legal liability or responsibility for any third party's use, or the results of such use, of any information, apparatus, product or process disclosed in this report, or represents that its use by such third party would not infringe privately owned rights. The views expressed in this paper are not necessarily those of the United States Government or the sponsoring agency. 


\title{
Irradiation Testing of Ultrasonic Transducers
}

\author{
J. Daw, B. Tittmann, Fellow, IEEE, B. Reinhardt, G. Kohse, P. Ramuhalli, Senior Member, IEEE, R. \\ Montgomery, H-T. Chien, J-F Villard, J. Palmer, and J. Rempe, Senior Member, IEEE
}

\begin{abstract}
Ultrasonic technologies offer the potential for high accuracy and resolution in-pile measurement of numerous parameters, including geometry changes, temperature, crack initiation and growth, gas pressure and composition, and microstructural changes. Many Department of Energy-Office of Nuclear Energy (DOE-NE) programs are exploring the use of ultrasonic technologies to provide enhanced sensors for in-pile instrumentation during irradiation testing. For example, the ability of single, small diameter ultrasonic thermometers (UTs) to provide a temperature profile in candidate metallic and oxide fuel would provide much needed data for validating new fuel performance models. Other efforts include an ultrasonic technique to detect morphology changes (such as crack initiation and growth) and acoustic techniques to evaluate fission gas composition and pressure. These efforts are limited by the lack of existing knowledge of ultrasonic transducer material survivability under irradiation conditions.

To address this need, the Pennsylvania State University (PSU) was awarded an Advanced Test Reactor National Scientific User Facility (ATR NSUF) project to evaluate promising magnetostrictive and piezoelectric transducer performance in the Massachusetts Institute of Technology Research Reactor (MITR) up to a fast fluence of at least $10^{21} \mathrm{n} / \mathrm{cm}^{2}(\mathrm{E}>0.1 \mathrm{MeV})$.

This test will be an instrumented lead test; and real-time transducer performance data will be collected along with temperature and neutron and gamma flux data. By characterizing magnetostrictive and piezoelectric transducer survivability during irradiation, test results will enable the development of novel radiation tolerant ultrasonic sensors for use in Material and Test Reactors (MTRs). The current work bridges the gap between proven out-of-pile ultrasonic techniques and in-pile deployment of ultrasonic sensors by acquiring the data necessary to demonstrate the performance of ultrasonic transducers.
\end{abstract}

Index Terms - In-Pile Instrumentation, Material and Test Reactors, Ultrasonic Transducers

Submitted May 17, 2013. Work supported by the US Department of Energy, Office of Nuclear Energy, Science, and Technology, under DOE-NE Idaho Operations Office Contract DE AC07 05ID14517.

J. Daw, J. Rempe, and J. Palmer are with the Idaho National Laboratory, P.O. Box 1625, MS 4112, Idaho Falls, ID, USA 38415-3840 (Joshua.Daw@inl.gov). B. Tittmann and B. Reinhardt are with the Pennsylvania State University, 212 Earth \& Engr. Sciences Building, University Park, PA, USA, 16802. G. Kohse is with the Massachusetts Institute of Technology, 77 Massachusetts Ave. Cambridge, MA 02139. P. Ramuhalli and R Montgomery are with Pacific Northwest National Laboratory, 902 Battelle Blvd. Richland, WA, USA 99354. H-T Chien is with Argonne National Laboratory, 9700 S. Cass Avenue Argonne, IL, USA 60439. J-F Villard is with the Commissariat à l'énergie atomique et aux énergies alternatives, Centre d'études de Cadarache, 13108 Saint-Paul-lezDurance, France.

\section{INTRODUCTION}

$\mathrm{A}^{\mathrm{N}}$ $\mathrm{N}$ effort has been initiated by the Department of EnergyOffice of Nuclear Energy (DOE-NE) to characterize the performance of candidate nuclear fuels during irradiation; especially in Material Test Reactor (MTR) tests used to qualify candidate new fuels. Ultrasonic measurements have a long and successful history of use for materials characterization, including detection and characterization of degradation and damage [1] as well as measurement of various physical parameters used for process control, such as temperature and fluid flow rate [2] and are used extensively in non-destructive evaluation (NDE). Although there are numerous types of ultrasonic sensors for measuring different properties of interest, all of these ultrasonic sensors incorporate a transducer; which can limit the survivability of such sensors in an irradiation test. The development of ultrasonic tools to perform a variety of in-pile measurements requires a fundamental understanding of the behavior of ultrasonic transducer materials in high-radiation environments. While a number of irradiation studies of ultrasonic transducers have been described in the literature, a one-to-one comparison of these studies is difficult, as the materials and test conditions often differ. In addition, the tests to date are generally at lower flux/fluences than what might be seen in US MTRs.

A Pennsylvania State University (PSU) -led effort for an ultrasonic transducer irradiation was selected by the Advanced Test Reactor National Scientific User Facility (ATR NSUF) for an irradiation in the Massachusetts Institute of Technology Nuclear Research Reactor (MITR). This test will be an instrumented lead test, allowing real time signals to be received from the transducers. The test is unique because it will be the first irradiation to include both piezoelectric and magnetostrictive transducers and because it will expose transducers to higher fluences than prior irradiations. Such a test will enable accurate measure of the degradation of candidate transducer materials under irradiation. As discussed in this paper, the test has also been designed to provide fundamental data on piezoelectric and magnetostrictive material performance in irradiation environments; hence, this data can be directly compared to results of prior irradiations.

\section{BACKGROUND}

Several US DOE-NE programs are investigating new fuels and materials for advanced and existing reactors. A primary objective of such programs is to characterize the irradiation performance of these fuels and materials. 
The key parameters needed to evaluate performance which could potentially be measured ultrasonically, as well as the desired accuracies and resolutions, are shown in Table I [3].
Similar measurement parameters exist for structural material tests.

TABLE I

Summary of desired fuel measurement parameters for irradiation testing.

\begin{tabular}{|c|c|c|c|}
\hline \multirow[t]{2}{*}{ Parameter } & \multirow[t]{2}{*}{ Representative Peak Value } & \multicolumn{2}{|c|}{ Desired } \\
\hline & & Accuracy & Spatial Resolution \\
\hline \multirow[t]{4}{*}{ Fuel Temperature } & Ceramic Light Water Reactor (LWR): $1400^{\circ} \mathrm{C}$ & \multirow[t]{4}{*}{$2 \%$} & \multirow{4}{*}{$\begin{array}{l}1-2 \mathrm{~cm} \text { (axially) } \\
0.5 \mathrm{~cm} \text { (radially) }\end{array}$} \\
\hline & Ceramic Sodium Fast Reactor (SFR): $2600^{\circ} \mathrm{C}$ & & \\
\hline & Metallic SFR: $1100^{\circ} \mathrm{C}$ & & \\
\hline & $\begin{array}{c}\text { Tristructural-isotropic (TRISO) High Temperature Gas } \\
\text { Reactor (HTGR): } 1250^{\circ} \mathrm{C}\end{array}$ & & \\
\hline \multirow[t]{3}{*}{ Cladding Temperature } & Ceramic LWR: $<400^{\circ} \mathrm{C}$ & \multirow[t]{3}{*}{$2 \%$} & \multirow[t]{3}{*}{$1-2 \mathrm{~cm}$ (axially) } \\
\hline & Ceramic SFR: $650^{\circ} \mathrm{C}$ & & \\
\hline & Metallic SFR: $650^{\circ} \mathrm{C}$ & & \\
\hline \multirow[t]{3}{*}{ Fuel Rod Pressure } & Ceramic LWR: $5.5 \mathrm{MPa}$ & \multirow[t]{3}{*}{$5 \%$} & \multirow[t]{3}{*}{ NA } \\
\hline & Ceramic SFR: $8.6 \mathrm{MPa}$ & & \\
\hline & Metallic SFR: $8.6 \mathrm{MPa}$ & & \\
\hline Fission Gas Release & $0-100 \%$ of Inventory & $10 \%$ & NA \\
\hline \multirow{4}{*}{$\begin{array}{l}\text { Fuel and Cladding } \\
\text { Dimensions and } \\
\text { Density }\end{array}$} & Initial Length: $1 \mathrm{~cm}$ & $1 \%$ & NA \\
\hline & Outer Diameter/Strain: $0.5 \mathrm{~cm} / 5-10 \%$ & $0.1 \%$ & NA \\
\hline & Fuel-Cladding Gap: 0-0.1 mm & $0.1 \%$ & NA \\
\hline & $\begin{array}{c}\text { Density: } \\
\text { Ceramic: }<11 \mathrm{~g} / \mathrm{cm}^{3} ; \text { Metallic: }<50 \mathrm{~g} / \mathrm{cm}^{3} \text {; } \\
\text { TRISO pebble } / \text { compact: } 2.25 \mathrm{~g} / \mathrm{cm}^{3}\end{array}$ & $2 \%$ & NA \\
\hline \multirow[t]{3}{*}{ Fuel Microstructure } & Grain size, $10 \mu \mathrm{m}$ & $5 \%$ & $1-10 \mu \mathrm{m}$ \\
\hline & Swelling/Porosity: 5-20\% & $2 \%$ & NA \\
\hline & Crack formation and growth & $2 \%$ & $10-100 \mu \mathrm{m}$ \\
\hline
\end{tabular}

Table II lists selected instrumentation available for irradiation tests in various international MTRs [4], which could potentially be replaced by ultrasonic transducer based sensors. It should be noted that many of the sensors used at foreign MTRs often require enhancement before they can be successfully deployed in the higher flux, harsher test conditions typical of US MTRs. If enhanced, these sensors can provide insights with respect to parameters, such as temperature, thermal conductivity, and crack growth. However, in general, the spatial resolution available with such sensors is limited due to the limited size of the irradiation test and the desire to minimize the impact of the sensor on test results. It should also be noted that existing and near-term sensor technologies do not provide any capability for detecting changes in fuel microstructure or constituent migration.

Ultrasonic measurements have a long and successful history of out-of-pile use for measurement of various process control parameters and non-destructive evaluation, including materials characterization and flaw detection. If it can be shown that the transducers used to make these measurements can survive irradiation test conditions, all of the parameters listed in Tables I and II could potentially be monitored ultrasonically with higher fidelity than possible with currently available sensors. For high accuracy measurements, most of these applications are likely to require the high frequency operation of piezoelectric transducers, but some measurements can be made with magnetostrictive transducers as well. For example, Post Irradiation Examinations (PIEs) have shown that fuel microstructural parameters, such as porosity and grain size, can be correlated to ultrasonic velocity [5]. As noted by Villard [6], frequency requirements for such measurements are typically restricted to greater than $10 \mathrm{MHz}$. However, lower frequencies can be used for some applications, such as ultrasonic thermometry, where frequency requirements may be $100-150 \mathrm{kHz}$ or lower (such as magnetostrictive transducer based ultrasonic thermometry). 
TABLE II

Selected instrumentation available in MTRs

\begin{tabular}{|c|c|c|}
\hline Parameter & Sensor & Comments \\
\hline \multirow[t]{5}{*}{ Temperature } & Melt Wires & $\begin{array}{l}\text { Peak value, resolution limited by number of wires, Post Irradiation } \\
\text { Examination (PIE) required }\end{array}$ \\
\hline & SiC Monitor & Peak value, $100-800{ }^{\circ} \mathrm{C}$ temperature range, PIE required \\
\hline & $\begin{array}{l}\text { Thermocouples (Types } \\
\text { N,K) }\end{array}$ & $1100{ }^{\circ} \mathrm{C}$ maximum operating temperature, constituent migration \\
\hline & $\begin{array}{l}\text { Thermocouples [Doped } \\
\text { Mo/Nb-alloy High } \\
\text { Temperature Irradiation } \\
\text { Resistant Thermocouples } \\
\text { (HTIR-TC)] }\end{array}$ & $1800^{\circ} \mathrm{C}$ maximum operating temperature, electrical insulation degradation \\
\hline & Thermocouples (Type C) & Decalibration due to transmutation caused by thermal neutron flux \\
\hline \multirow[t]{2}{*}{ Density/Displacement } & $\begin{array}{c}\text { Linear Variable } \\
\text { Differential Transformer } \\
\text { (LVDT) }\end{array}$ & Qualified to $500{ }^{\circ} \mathrm{C}$ \\
\hline & Diameter Gauge & Qualified to $500{ }^{\circ} \mathrm{C}$ \\
\hline $\begin{array}{l}\text { Crack } \\
\text { Initiation/Growth }\end{array}$ & $\begin{array}{c}\text { Direct } \\
\text { Current Potential Drop } \\
\text { (DCPD) Method }\end{array}$ & Sensitive to water chemistry, accuracy limited to $\sim 20 \%$ \\
\hline Young's Modulus & Loaded Creep Specimen & LVDT based measurement, accuracy limited to $\sim 10 \%$ \\
\hline
\end{tabular}

\section{ULTRASONIC TRANSDUCERS}

To generate and receive ultrasonic pulses and signals, two of the most commonly used technologies are piezoelectric and magnetostrictive transducers. Ultrasonic measurements using piezoelectric transducers have been demonstrated over a wide frequency range from $\mathrm{kHz}$ and up to $\mathrm{GHz}$; however, most nondestructive examination (NDE), materials characterization, and process monitoring are performed in the range from 1-20 $\mathrm{MHz}$, making piezoelectric transduction ideal. The current capabilities of magnetostrictive transducers are typically limited to operation at frequencies up to the order of $100 \mathrm{kHz}$, although recent research suggests that higher frequencies may be possible for small magnetostrictive transducers [7]. However, mechanical coupling as well as enhanced guided wave mode generation makes magnetostrictive transduction ideal for low frequency measurements, such as ultrasonic thermometry [8]. Therefore, radiation tolerant sensors which utilize piezoelectric or magnetostrictive materials are being considered as candidates for instrumentation for use in US MTR testing. As noted above, the PSU-led MITR irradiation test is unique because it will include both piezoelectric and magnetostrictive transducers.

\section{A. Piezoelectric Transducers}

The piezoelectric transducer design proposed for this irradiation test were selected based on research by Parks and Tittmann [9] and from early ultrasonic sensors developed at the Hanford Engineering Development Laboratory (HEDL) [10] for under-sodium viewing which shared many similar constraints with respect to thermal and neutron radiation tolerance. The transducers rely on pressure for coupling the piezoelectric element to the waveguide. Electrical contact with the piezoelectric element is also achieved through application of pressure. A backing layer behind the piezoelectric sensor provides damping and prevents excessive "ringing" of the transducer. In the current design, the backing layer material is a carbon/carbon composite. A schematic of the piezoelectric transducer design is shown in Figure 1.

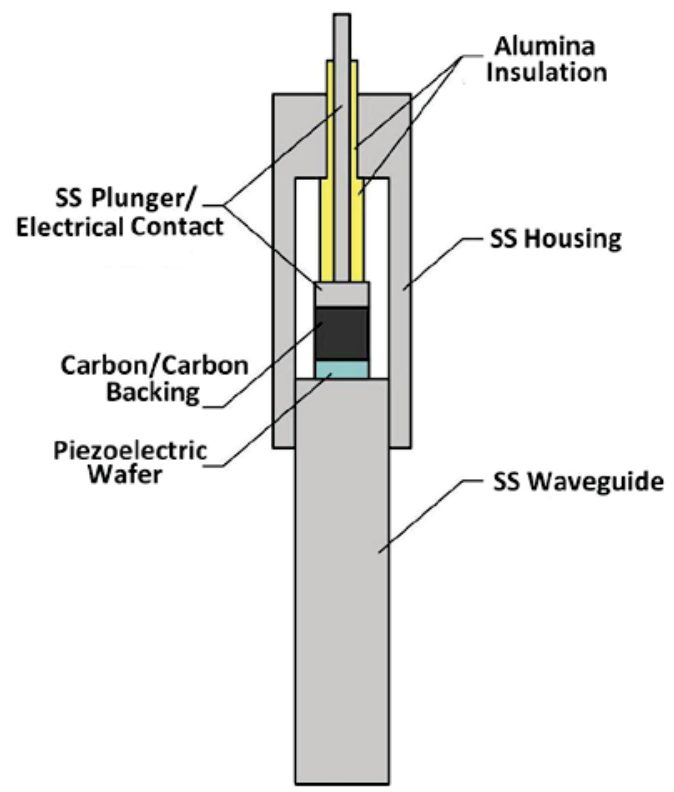

Fig. 1. Schematic of piezoelectric transducer design.

Due to volume limitations in this irradiation test, a limited number of piezoelectric transducer materials can be included. Piezoelectric transducer materials were selected based on prior 
irradiation test results, anticipated radiation tolerance, transition temperature, and ease of incorporation into sensor designs. The piezoelectric materials selected for inclusion in this test are described below.

1) Bismuth Titanate

A literature review revealed bismuth titanate is the most promising material extensively tested to date [11]. However, this material lost roughly $60 \%$ of its one way piezoelectric response at a fast neutron fluence of $10^{20} \mathrm{n} / \mathrm{cm}^{2}$; suggesting that it is not an ideal candidate. The decrease in the signal response is in agreement with the statements provided in Reference [12], which indicates that disordered Ti-O-Ti bridges of highly covalent character form in titanates when subjected to neutron radiation effects. Given that this material has shown the greatest promise to date, it has been selected as a baseline for comparison in this irradiation test.

2) Aluminum Nitride

Aluminum nitride is a relatively new bulk single crystal material. In fact, the work of Parks and Tittmann with this material is the first of its sort. In the past, thin film AlN has been shown to be unaffected by gamma irradiation up to 18.7 MGy [13] and temperatures of $1000{ }^{\circ} \mathrm{C}$. [14,15] Moreover, this material has been explicitly cited in numerous independent studies as a highly radiation tolerant ceramic [12]. This is thought to be at least partially due to its wurzite crystal structure. Further, tests of bulk single crystal AIN in a TRIGA Training, Research, Isotopes, General Atomics (TRIGA) nuclear reactor core showed this material to be completely unaffected by fast and thermal neutron fluences of $1.85 \times 10^{18}$ $\mathrm{n} / \mathrm{cm}^{2}$ and $5.8 \times 10^{18} \mathrm{n} / \mathrm{cm}^{2}$, respectively, and a gamma dose of 26.8 MGy [9]. This work, along with that of Yano [16] and Ito [17], have indicated that the ${ }^{14} \mathrm{~N}(n, p){ }^{14} \mathrm{C}$ is not of concern; and AlN is an excellent candidate material.

3) Zinc Oxide

Zinc oxide, like AlN, has a wurzite crystal structure and has been cited as a highly radiation tolerant material [12]. The evaluated nuclear data files (ENDF) do not show any detrimental nuclear cross sections, and this material possesses a high transition temperature and moderate piezoelectric coupling (a measure of the efficiency in converting electrical energy to mechanical energy).

\section{B. Magnetostrictive Transducers}

The magnetostrictive transducer design proposed for this test was selected based on research by Lynnworth [18] and Daw [19]. The magnetostrictive transducers consist of a small driving/sensing coil, a biasing magnet, and a magnetostrictive waveguide. The ultrasonic signal is generated when a high frequency alternating current pulse is driven through the coil. The induced magnetic field causes magnetic domains within the material to oscillate. The domains are pre-biased by the magnet to maximize the response. Received echoes are detected through the reciprocal effect. A schematic of the magnetostrictive transducer design is shown in Figure 2.

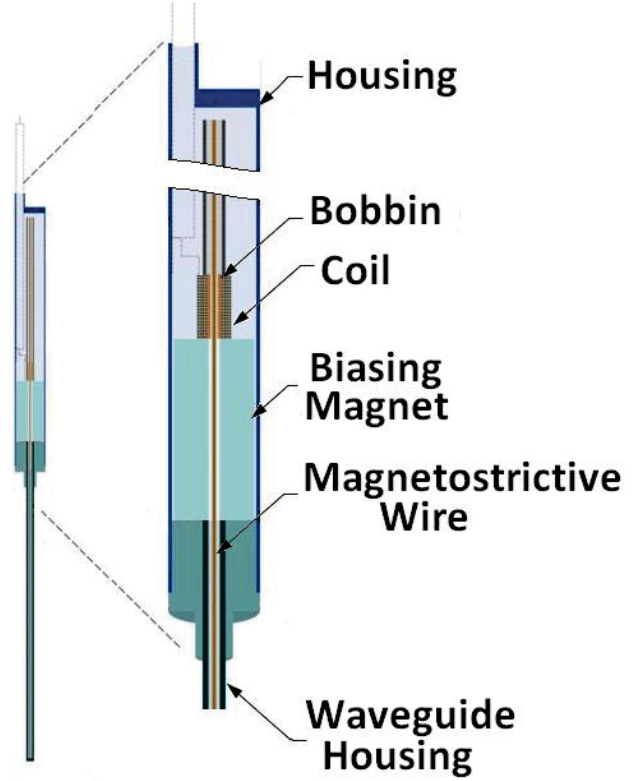

Fig. 2. Schematic of magnetostrictive transducer design.

The magnetostrictive transducer materials were selected based on previous use in radiation environments, amounts of neutron sensitive materials, Curie temperature, and saturation magnetostriction.

\section{1) Remendur}

Remendur has the most history of use in nuclear applications of all the magnetostrictive alloys, having been used previously for short duration thermometry applications. Remendur has a high Curie temperature $\left(950{ }^{\circ} \mathrm{C}\right)$ and relatively high saturation magnetostriction ( $\sim 70 \mu$ strains). Remendur is an alloy composed of approximately $49 \%$ iron, $49 \%$ cobalt, and $2 \%$ vanadium. Because of its cobalt content, Remendur is not considered to be an ideal choice (due to concerns about the production of Cobalt-60 during irradiation). However, its successful prior use warrants inclusion.

2) Galfenol [20]

Galfenol is a relatively new alloy of iron and gallium (approximately 13\% gallium). Galfenol is a member of the "giant" magnetostrictive alloys and has a very large saturation magnetostriction (100-400 $\mu$ strains). It also has an appropriately high Curie temperature $\left(700{ }^{\circ} \mathrm{C}\right)$. Neither of its constituent elements react strongly with neutron radiation. These factors suggest that Galfenol is the most appealing magnetostrictive material candidate.

3) Arnokrome [21-23]

Arnold Magnetics produces several magnetostrictive alloys, Arnokrome 3, Arnokrome 4, and Arnokrome 5. Arnokrome 3 contains cobalt has much lower magnetostriction than Remendur and is therefore not of interest in the current study. Arnokrome 4 and 5 have similar magnetostriction to Arnokrome 3, but without the presence of cobalt. Initial testing of transducers constructed using the Arnokrome alloys indicates that the signal will decrease with increasing temperatures to the extent that the signal will become indistinguishably small at the temperatures expected in the 
irradiation test. Therefore, Arnokrome will only be included as "tuck in" samples which will be tested during PIE (see Section IVC).

\section{EXPERIMENT DESIGN}

\section{A. $M I T R$}

The MITR is a tank-type research reactor [24] operating at atmospheric pressure. It began operation in 1958; and its current license, issued in November 2012, authorizes steadystate $6 \mathrm{MW}$ operation. The reactor has two tanks: an inner tank for light water coolant/moderator and an outer tank for the heavy water reflector. A graphite reflector surrounds the heavy water tank. The MITR is equipped with a wide variety of sample irradiation facilities, with fast and thermal neutron fluxes up to $3.6 \times 10^{13}$ and $1.2 \times 10^{14} \mathrm{n} / \mathrm{cm}^{2} \cdot \mathrm{s}$ respectively. The test position within the MITR core is shown in Figure 3.

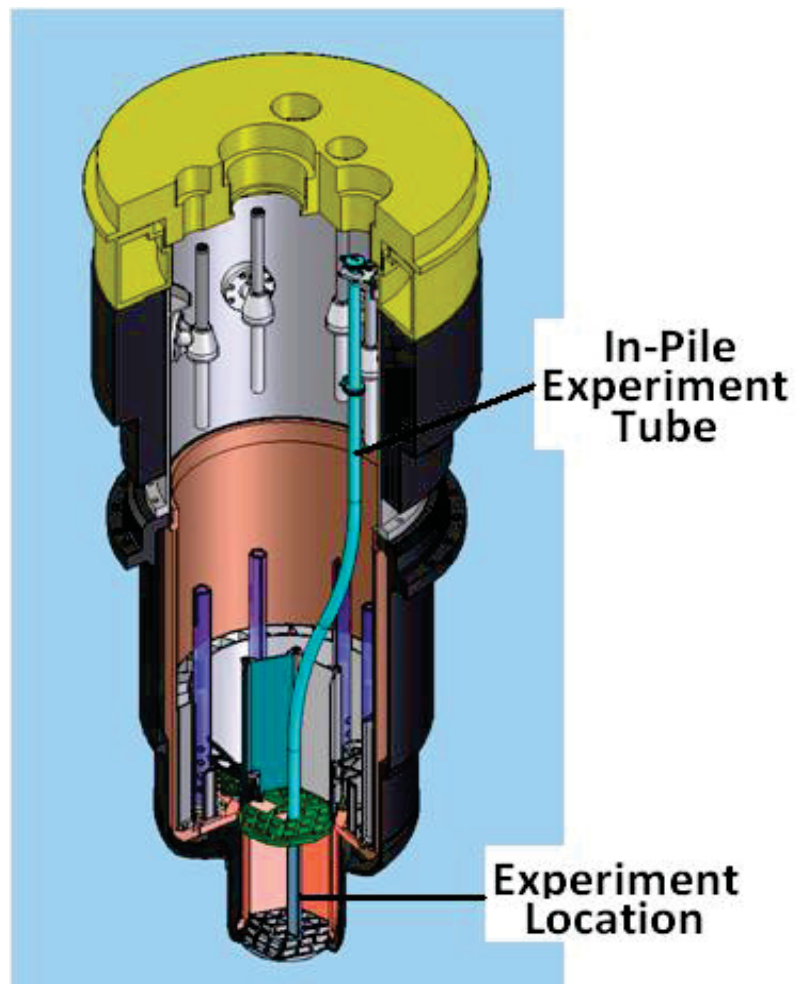

Fig. 3. Schematic cutaway view of the MITR reactor showing the locations of the in-pile experiment tube and the experiment location within the core.

\section{B. Irradiation Conditions}

Temperature will be controlled by a helium/neon gas gap with adjustable gas composition. The proposed test temperature will be approximately $400{ }^{\circ} \mathrm{C}$. It is proposed that the test exceed fast neutron fluences of prior piezoelectric transducer irradiations (e.g., $>1 \times 10^{21} \mathrm{n} / \mathrm{cm}^{2}$ [25]). In order to observe rapid changes at relatively low fluences, it is proposed to start the test with the reactor slowly ascending to power. Hence, it is anticipated that the capsule will be irradiated for at least 310 days. The identified irradiation position and flux conditions at the MITR are summarized in Table III.
TABLE III

Expected irradiation test conditions. MITR In-Core Experimental Facility

Capsule dimensions: $42 \mathrm{~mm}$ OD x $152.4 \mathrm{~mm}$ long

Thermal Flux: $3.6 \times 10^{13} \mathrm{n} / \mathrm{cm}^{2} \cdot \mathrm{sec}$

Fast Flux $(>1 \mathrm{MeV}): 1.2 \times 10^{14} \mathrm{n} / \mathrm{cm}^{2} \cdot \mathrm{sec}$ Gamma dose rate: $1 \times 10^{9} \mathrm{r} / \mathrm{hr}$ Temperature: $350{ }^{\circ} \mathrm{C}-400{ }^{\circ} \mathrm{C}$

Testing Period: 310 Effective Full Power Days requiring approximately 540 calendar days (18 months)

\section{Capsule}

The MITR configuration restricts the test capsule to a cylinder $42 \mathrm{~mm}$ in diameter and $152.4 \mathrm{~mm}$ in length (see Figure 4). The currently proposed capsule design uses structural graphite as a holder material. Graphite is an ideal material as it has low density (for reduced gamma heating). In addition, graphite is thermally conductive (to produce a uniform predictable temperature), exhibits low neutron activation, and can be used at very high temperatures. During the irradiation, the graphite will hold the test specimens in place while also efficiently conducting heat generated to the coolant.

Based on estimated space requirements for each transducer, it is proposed to include six piezoelectric samples and three magnetostrictive samples. Additionally, loose 'tuck in' samples of each test material will be included. This will allow for Post Irradiation Examination (PIE) of samples even if the transducers cannot be dismantled after the irradiation.

An array of sensors will be included in the irradiation capsule to ensure that test conditions are well-characterized. Two type-K thermocouples and melt wires will be used to monitor temperatures online and verify maximum test temperature. Thermal neutron flux will be monitored online using a vanadium emitter Self-Powered Neutron Detector (SPND), and thermal and fast flux will be verified using flux wires. Gamma flux will be monitored online using a platinum emitter Self-Powered Gamma Detector (SPGD). 


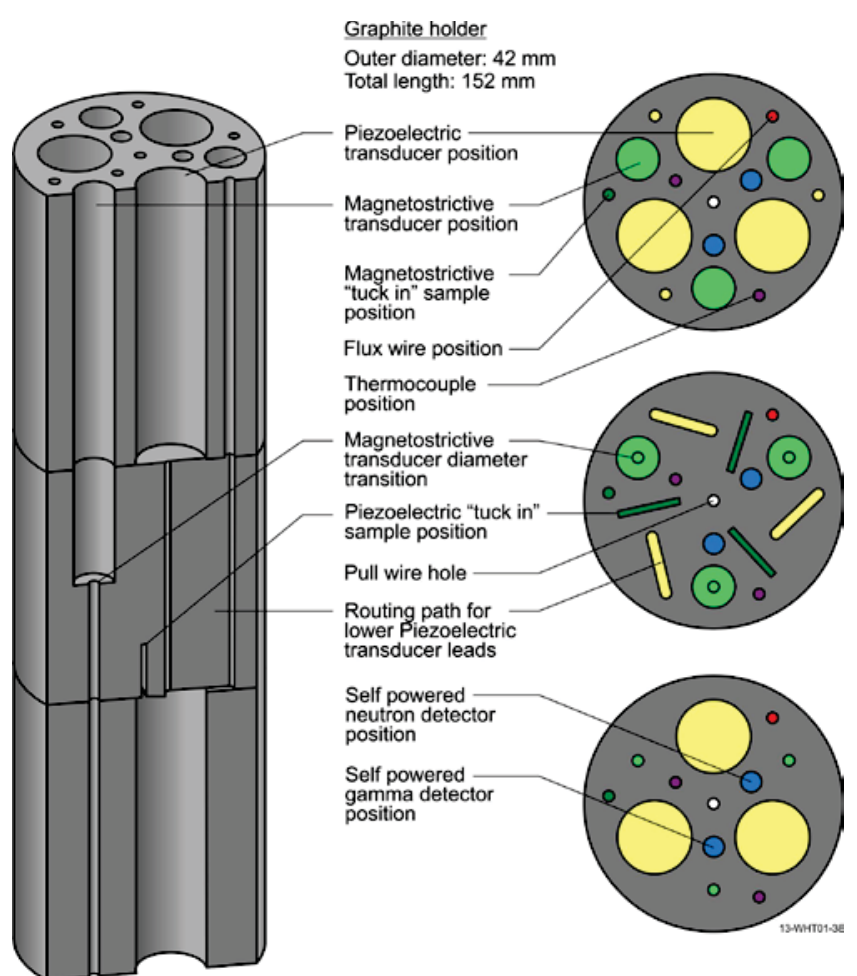

Fig. 4. Schematic of three piece graphite capsule design showing positions of test transducers and sensors.

\section{Laboratory Tests}

A series of laboratory tests will be performed in furnaces in order to separate the effects of elevated temperatures from the irradiation effects on the transducers. These tests will also help optimize the transducer designs for thermal cycling and for high temperature, long duration operation.

Temperature cycling tests will first be performed to identify heating rate limitations (i.e. thermal shock) of each sample material.

The second planned test will evaluate the maximum operating temperature of each transducer.

Finally, a long duration test will be performed that will closely match the temperatures and duration of the in-reactor test. This test will begin with a slow temperature ramp, matching the initial power up temperatures in the reactor. The test will operate at the anticipated steady state in-core temperature, approximately $400{ }^{\circ} \mathrm{C}$ with intermittent cool downs simulating scheduled reactor shut downs. The test will operate for up to 18 months (the anticipated in-pile test duration).

\section{E. Post Irradiation Examination}

The irradiation effects on the candidate materials will be quantified through PIE, and results will be compared with preirradiation values. A description of the planned PIEs follows.

Simple pulse echo measurements, which reveal a great deal of information about the quality of the transducer, will first be completed. These measurements can be performed without disassembling the transducer. They can be made in-pile (after reactor shut down) and after removal from the reactor. The pulse-echo measurement is used to measure signal to noise ratio (indicating sensitivity of the transducer), resonance frequency, bandwidth, and the quality factor (a measure of the intrinsic damping of the crystal). These are used as a go/no go test for sensor performance and are most important in ascertaining transducer performance.

Impedance measurements can be used to calculate the loss tangent ${ }^{1}$, which is related to the dielectric property changes, as well as the resonance frequency, stiffness, and dielectric constant. This is important in determining loss mechanisms. This measurement can also be made without disassembling the transducer.

Hysteresis measurements can show remnant polarization, which is necessary for transduction in ferroelectrics as well as the degradation mechanism, such as metamictization ${ }^{2}$ versus antiferroelectric tendencies ${ }^{3}$. This measurement can be made without disassembling the transducer.

Density data are needed to determine material properties from the pulse-echo and impedance measurements. During temperature testing, it is common to see variations in densities of many piezoelectric materials; and it is important to characterize these changes. The sensor material must be removed from the transducer assembly for this measurement.

The d33 parameter is a material constant and important to piezoelectric transducer signal amplitude. This parameter is most significantly affected during neutron testing in most materials, and it is also important to characterize observed $\mathrm{d} 33$ changes. It will be necessary to remove the sensor material from the transducer in order to measure this material property.

Some materials change color during irradiation, which can indicate absorption of oxygen and other contaminants. Optical examination would require the sensor material to be removed from the assembly and photographed with a high resolution camera.

Scanning Electron Microscopy (SEM) is important to characterizing the grain structure of the sensor and changes that occur during irradiation. SEM examinations may provide insights about the damage mechanisms and how polar domains change during irradiation. SEM examples also require that samples be removed from the transducer assembly.

\section{CONCLUSION}

Ultrasonic measurements have a long and successful history of use for materials characterization, measurement of various physical parameters used for process control, and NDE. To enable the development of advanced in-core sensors based on ultrasonic technologies, a fundamental understanding of the behavior of ultrasonic transducer materials in high-radiation environments is needed. While a number of irradiation studies of ultrasonic transducers have been performed, a direct comparison of these studies is difficult, due to differences in the included materials and test conditions. In addition, the tests to date have generally been performed at lower flux/fluences

\footnotetext{
${ }^{1}$ A measure of electrical energy dissipation of the crystal.

${ }^{2}$ The process through which a crystal becomes amorphous through damage processes; in this case neutron radiation, causing a loss of piezoelectricity.

${ }^{3} \mathrm{~A}$ loss of piezoelectricity through depolarization.
} 
than what might be required for US MTRs.

A PSU-led effort to perform an ultrasonic transducer irradiation is being funded by the ATR NSUF for irradiation in the MITR. The test is unique because it will be the first irradiation to include both piezoelectric and magnetostrictive transducers and because it will expose transducers to higher fluences than prior irradiations. This test will be an instrumented lead test, such that real time signals are received from the transducers. Such a test will enable an accurate measurement of the performance and degradation of candidate piezoelectric and magnetostrictive transducer materials under irradiation. As discussed in this paper, the irradiation program is being developed so that results will identify an appropriate ultrasonic transducer material to enable development of new ultrasonic sensors capable of monitoring many physical parameters in-core.

\section{REFERENCES}

[1] D. Ensminger, and L. J. Bond, Ultrasonics; Fundamentals, Technologies, and Applications, CRC Press, 2012.

[2] L.C. Lynnworth, "Ultrasonic Measurements for Process Control: Theory, Techniques, and Applications," Academic Press, 1989.

[3] J. Rempe, H. MacLean, R. Schley, D. Hurley, J. Daw, S. Taylor, J. Smith, J. Svoboda, D. Kotter, D. Knudson, S. C. Wilkins, M. Guers, L. Bond, L. Ott, J. McDuffee, E. Parma, and G. Rochau, New In-Pile Instrumentation to Support Fuel Cycle Research and Development, FCRD-FUEL-2011-000033 (also issued as INL/EXT-10-19149), January 2011.

[4] B. G. Kim, J. L. Rempe, J-F Villard, and S. Solstad, "Review of Instrumentation for Irradiation Testing of Fuels and Materials," invited review paper, Nuclear Technology, 176, November 2011, p 155-187..

[5] K. Phani, et. al, "Estimation of Elastic Properties of Nuclear Fuel Material Using Longitudinal Ultrasonic Velocity - A New Approach," J. Nucl. Mat., 366, 2007, pp. 129-136.

[6] J. F. Villard, et. al.," Acoustic Sensor for In-Pile Fuel Rod Fission Gas Release Measurement," IEEE Transactions on Nuclear Science, 58, 2011, pp. 151-155.

[7] J.E. Daw, J.L. Rempe, J.C. Crepeau, "Update On Ultrasonic Thermometry Development At Idaho National Laboratory," accepted paper for NPIC-HMIT, 2012.

[8] N. Gopalsami, A.C. Raptis, "Acoustic Velocity and Attenuation Measurements in Thin Rods with Application to Temperature Profiling in Coal Gasification Systems," IEEE Transactions on Sonics and Ultrasonics, $S U-31,1984$, pp. 32-39.

[9] D.A. Parks, B. R. Tittmann. "Ultrasonic NDE in a Reactor Core," Presented at Review of Progress in Quantitative Nondestructive Evaluation, July 17-22, Burlington, VT, 2011.

[10] R.N. Ord, R.W. Smith, "Ultrasonic Under-Sodium Viewing System Development for the FFTF," HEDL-SA-335. Westinghouse Hanford Co., Richland, Washington, 1972.

[11] Y. P. Meleshko, S. G. Karpechko, G. K. Leont'ev, V. I. Nalivaev, A. D. Nikiforov, and V. M. , "Radiation Resistance of the Piezoelectric Ceramics TrsTS-21 and TNV-I," Translated from Atomnaya Energiya, 1986, pp. 50-52.

[12] K. Trachenko, "Understanding resistance to amorphization by radiation damage," Journal of Physics: Condensed Matter, 16(49), 2004, pp. R1491-R1515.

[13] R. Kazys, V. Voleisis, R. Sliteris, B. Voleisiene, L. Mazeika, and H. Abderrahim, "Research and Development of Radiation Resistant Ultrasonic Sensors for Quasi-Image Forming Systems in a Liquid LeadBismuth." Ultragarsas (Ultrasound), 62(3), 2006, pp. 7-15.

[14] N. D. Patel, and P. S. Nicholson, "High Frequency - High Temperature Ultrasonic Transducers," NDT International, pp. 262-266, 1990.

[15] D. Stubbs, and R. Dutton , "High-Temperature Ultrasonic Sensor for in Situ Monitoring of Hot Isostatic Processing," SPIE, 1996, pp. 164-172.

[16] T. Yano, K. Inokuchi, M. Shikama, and J. Ukai, "Neutron irradiation effects on isotope tailored aluminum nitride ceramics by a fast reactor up to $2 \cdot 10^{26} \mathrm{n} / \mathrm{m}^{2}$," Journal of Nuclear Materials, 2004, pp. 1471-1475.
[17] Y. Ito, et al., "Radiation Damage of Materials Due to High Energy Ion Irradiation," Nuclear Instruments and Methods in Physics Research, $530,2002$.

[18] L.C. Lynnworth, E.H. Carnevale, M.S. McDonough, S.S. Fam, "Ultrasonic Thermometry for Nuclear Reactors," IEEE Transactions on Nuclear Science, Vol. NS-16, pp. 184-187, 1968.

[19] J. Daw, J. Rempe, S. Taylor, J. Crepeau, and S.C. Wilkins, "Ultrasonic Thermometry for In-Pile Temperature Detection," Proceedings of NPIC\&HMIT 2010, 2010.

[20] "What is Galfenol?", Etrema Products, Inc., http://www.etremausa.com/core/galfenol/, Accessed 08/09/2012.

[21] Arnokrome 3 Datasheet Rev. 01-11-11, www.arnoldmagnetics.com/WorkArea/DownloadAsset.aspx?id=5262, Accessed 08/09/2012.

[22] Arnokrome 4 Specification Rev. 1/11/11, www.arnoldmagnetics.com/WorkArea/DownloadAsset.aspx?id=5263, Accessed 08/09/2012.

[23] Arnokrome 5 Specification Rev. 2/24/11, www.arnoldmagnetics.com/WorkArea/DownloadAsset.aspx?id=5328, Accessed 08/09/2012.

[24] MITR Users Guide Rev. 3 July 2012, Massachusetts Institute of Technology (2012).

[25] F. Augereau, J-Y. Ferrandis, J-F. Villard, D. Fourmentel, M. Dierckx, J. Wagemans, "Effect of intense neutron dose radiation on piezoceramics", Acoustics'08, Paris, 2008. 